\title{
A JOINT MODEL OF PARTICIPATION IN NON-WORK ACTIVITIES AND TIME-OF-DAY CHOICE SET FORMATION FOR WORKERS
}

\author{
Marisol Castro \\ The University of Texas at Austin \\ Dept of Civil, Architectural \& Environmental Engineering \\ 1 University Station C1761, Austin, TX 78712-0278 \\ Tel: 512-471-4535, Fax: 512-475-8744 \\ Email: mcastro@mail.utexas.edu \\ Naveen Eluru \\ McGill University \\ Department of Civil Engineering and Applied Mechanics \\ 817 Sherbrooke Street West, Montreal, Quebec, Canada H3A 2K6 \\ Tel: 514-398-6856, Fax: 514-398-7379 \\ Email: naveen.eluru@mcgill.ca \\ Chandra R. Bhat* \\ The University of Texas at Austin \\ Dept of Civil, Architectural \& Environmental Engineering \\ 1 University Station C1761, Austin, TX 78712-0278 \\ Tel: 512-471-4535, Fax: 512-475-8744 \\ Email: bhat@mail.utexas.edu \\ Ram M. Pendyala \\ Arizona State University \\ School of Sustainable Engineering and the Built Environment \\ Room ECG252, Tempe, AZ 85287-5306 \\ Tel: 480-727-9164; Fax: 480-965-0557 \\ Email: ram.pendyala@asu.edu \\ *corresponding author
}




\begin{abstract}
Non-work activity and travel participation is an important component of overall travel demand that is complex to model as the greater degrees of flexibility associated with such travel induces larger variability and randomness in this behavior. This paper aims to offer a framework for modeling the participation in and travel mileage allocated to non-work activities during various time periods of the day for workers. Five time-of-day blocks are defined for workers based on the period of the day in relation to the work schedule. Individuals can choose to pursue non-work activities in one or multiple time blocks and travel miles to accomplish the activities. A multiple discrete-continuous extreme value (MCDEV) modeling approach is employed to model this phenomenon. A unique element of the paper is the addition of a latent choice set generation model as a first component in the model system. This choice set generation model can be used to determine the set of time-of-day periods that each individual will consider for the pursuit of non-work activities, while recognizing the fact that the consideration choice set is not explicitly observed (and is therefore latent) by the analyst. Thus, the model system presented in this paper is capable of modeling non-work activity engagement and associated travel mileage by time-ofday period while incorporating varying choice sets across individuals. The two-component model system is applied to a survey sample drawn from the San Francisco area of the United States, and shown to perform substantially better than a pure MDCEV model that assumes a constant choice set across the sample.
\end{abstract}




\section{INTRODUCTION}

Urban areas around the world are experiencing increasing levels of travel demand and vehicular miles of travel, particularly in rapidly growing regions of the globe (1). Although transportation professionals have traditionally focused on work-related travel and the commute journey in an effort to manage peak period congestion, it is becoming increasingly clear that non-work travel demand, which tends to be more discretionary and exhibits greater variability across the population, is a critically important component of overall travel demand in a metropolitan region. In developed nations, at least, it appears that many of the factors that historically contributed to increases in work travel demand are approaching saturation (e.g., women's labor force participation rate), and that increases in travel demand over time can largely be attributed to increases in non-work discretionary travel $(2,3)$. These increases in non-work travel have been made possible by efficiencies in lifestyles (due to technological innovations, transition to a service-oriented economy), smaller household sizes and reduced household constraints, and increases in real income. These phenomena are now being witnessed worldwide, calling attention to the need to accurately understand the nature of non-work activity participation and the travel associated with such activity engagement.

The need to accurately model non-work activity participation and associated travel is also critical in the context of the development and specification of activity-based travel model systems that focus on tours (or trip chains) as the unit of analysis. In these model systems, travel patterns are simulated for each individual in a synthetic population while recognizing that individual trips do not exist in isolation, but are often linked or chained together into tours. In a tour-based framework, one is interested in modeling non-work activity stops that may occur in different tours, and the travel associated with such stops.

This paper focuses on jointly modeling worker participation in and travel mileage for non-work activities. Evidence in the literature suggests that workers are increasingly participating in non-work activities, particularly in conjunction with the commute to or from work. Gordon et al. (4) measured the growth of non-work travel using the 1977 and 1983 Nationwide Personal Transportation Survey (NPTS) in the United States, and particularly noted the growth in such travel during the work-to-home commute. Lockwood and Demetsky (5) also noted that a large number of individuals made one or more stops during the return home commute journey. Strathman and Dueker (6) analyzed the 1990 NPTS data and noted that nearly 20 percent of non-work activities were part of the daily commute for workers. More recently Hu and Young (7) and Toole-Holt et al. (3) reported that increases in overall travel demand may be largely attributed to growth in non-work travel. McGuckin et al. (8) report an increase in trip chaining, particularly among men on the journey from home to work, and note that this increase in trip chaining is largely due to non-work stops for coffee and breakfast.

There is a large body of literature devoted to the analysis of non-work travel; it is impossible to provide an exhaustive literature review within the scope of this paper. Adler and Ben-Akiva (9) and Horowitz (10) are early examples of studies that modeled various choice dimensions of non-work activity-travel engagement including frequency, duration, destination, and mode choices. These studies largely constituted sequential model systems employing discrete choice models founded on utility maximization frameworks. Strathman et al. (11) attempt to provide a more comprehensive framework for modeling non-work travel in a trip chaining context by considering a typology of trip chaining patterns defined by the number of stops undertaken during a tour. Their trip chain based approach for analyzing non-work activity engagement patterns serves as a basis for the approach adopted in this paper. Non-work travel 
has been modeled in the context of simulating overall daily activity schedules of individuals (e.g., 12, 13). Studies examining the influence of socio-economic characteristics and land use density and diversity measures on non-work travel indicate that there are numerous factors affecting such travel engagement decisions, and that non-work travel tends to be highly variable in nature, thus making it considerably challenging to accurately model non-work activity-travel demand $(14,15)$.

Given the importance of and increasing emphasis being placed on modeling non-work travel engagement, this paper aims to contribute further to this body of literature by providing a framework for jointly modeling worker's participation in and miles of travel for non-work travel in time-of-day blocks or periods that can be defined in relation to the work schedule. The model system proposed in this paper may be considered a high-level framework that first considers the decision of whether to participate at all in non-work activities and the total travel mileage to devote to such travel. Only these two dimensions of non-work activity participation are considered in this paper due to their natural importance from a travel demand management perspective, and also to keep model system computationally tractable while also modeling all the non-work participations jointly. In this regard, one could make the case that participation and time-use would be more appropriate as a high-level model, but we instead choose to model participation and mileage because of the increasing emphasis in the field on energy consumption, greenhouse gas emissions, and air quality forecasting. At the same time, our high-level model can inform the subsequent and finer modeling of activity purpose/types, time allocation, destinations, and frequencies within each time-of-day block defined in relation to the work schedule.

The behavioral paradigm and modeling considerations that shaped the structure and specification of the model system developed in this study is described in detail in the next section. The third section presents the modeling methodology and formulation, while the fourth section provides a description of the data set used for the empirical component of this paper. The fifth section presents model estimation results while the sixth section offers concluding thoughts.

\section{BEHAVIORAL CONSIDERATIONS IN MODELING NON-WORK TRAVEL}

As mentioned in the introductory section, this paper considers the joint choice of whether to participate in and the amount of mileage to devote to non-work activities within specified timeof-day periods or blocks for workers. For workers, it is possible to identify five time periods as follows $(16,17)$ :

- Before work tour, representing activities that are part of tours that start and end at home prior to the commencement of the first work episode of the day

- During home-to-work tour, representing non-work activities undertaken on the way to work

- Work based tour, representing non-work activities undertaken as part of tours that begin and end at the work location

- During work-to-home tour, representing non-work activities undertaken on the way home from work

- After work tour, capturing non-work activities undertaken as part of separate home-based tours made after arriving home from work 
There are several key dimensions worth noting in the context of the behavioral choices considered in this paper. First, there is a continuous choice element represented by the amount of mileage devoted to non-work travel. Second, and more consequential to the contribution of this paper, is the multiple discrete nature of the choice of whether to participate in non-work activities during the defined time periods. Individuals may choose to participate in non-work activities during none, one, or more than one period identified previously. Thus, the choice of period in which to participate in a non-work activity is not a single discrete choice problem, but a multiple discrete problem. The total mileage in non-work activity-related travel is apportioned or allocated across the non-work activity engagement in the various time-of-day blocks. This leads one to adopt the multiple discrete-continuous extreme value (MDCEV) model formulation that has now been applied in numerous contexts to jointly model discrete-continuous problems of this type (18). The MDCEV model offers an appropriate approach for jointly modeling non-work activity participation during a time period as well as the mileage traveled to pursue such activities, effectively tying activity engagement with the associated travel mileage.

There is an additional important consideration in the context of this study that helps complete the behavioral paradigm adopted in this paper. This consideration is related to the notion of choice set generation or choice set formation in discrete choice modeling. In the context of the behavioral choices modeled in this paper, it is entirely possible that some individuals may not consider all five time-of-day blocks for undertaking non-work activities. Instead, certain individuals - depending on a variety of factors - may consider only a subset of the time-of-day blocks for undertaking non-work activities. In other words, one must consider the possibility that the choice set is not constant, but variable, across the population. This necessitates the inclusion of a component capable of modeling choice set generation or composition within the framework adopted for this study.

The importance of choice set consideration has been recognized widely in the transportation literature (e.g., 19-21). Unfortunately, as in many choice contexts, it is not possible to explicitly identify the choice set for each individual as such information is virtually never included in an activity-travel survey data set. The analyst must determine the feasible choice set for each individual based on a variety of criteria or rules. In the context of this study, it is particularly challenging as it is difficult to develop a universal set of criteria or rules to define the time-of-day choice set composition for each individual. Manski (22) proposed a twostage approach for tackling problems of this nature. In the first stage, the choice set is generated as a subset of the universal choice set, and in the second stage, the individual selects alternatives conditional on the choice set. Some applications of this approach in the single discrete choice context can be found in Basar and Bhat (21), McFadden (23), Swait and Ben-Akiva (24) and Cantillo and Ortuzar (25). The uniqueness of the current study is that the two-stage approach involving choice set generation is employed in the context of a multiple discrete choice situation mixed with a continuous choice dimension (travel mileage). An exception is the work by von Haefen (26) who does employ a two-stage approach in the context of a multiple discrete choice problem, but his model formulation is different from that of the MDCEV (18) which offers a more computationally tractable closed form expression for parameter estimation and cleanly collapses to the traditional multinomial logit (MNL) form when the number of alternatives chosen is one.

Another important reason for modeling choice set consideration is the flexibility to accommodate non-compensatory behavior in the choice process. If a choice alternative does not meet the constraints or conditions for its inclusion, then it is eliminated from the choice set 
regardless of its attributes and its relation to other choice alternatives in the choice set. Estimating a compensatory model ignoring such non-compensatory behavior will lead to incorrect estimation of the impacts of variables on choice dimensions of interest. In this paper, a latent choice set generation model is proposed to recognize the latent (unobserved or hidden) nature of the choice set determination process. This is a non-compensatory model as opposed to the second stage choice model, which does accommodate compensatory choice behavior.

There has been considerable work on the development of latent choice set generation models, and this study employs these techniques in conjunction with the MDCEV model. Swait and Ben-Akiva (24) indicate that choice set formation is a constrained process that should consider informational, psychological, cultural, and social restrictions. Shocker et al. (27) identifies four levels of choice set formation, including the universal set of all alternatives, the awareness set, the consideration set, and finally, the actual choice set. Ben-Akiva and Boccara (28) develop a probabilistic choice set generation model considering individual heterogeneity with a focus on incorporating the effects of non-compensatory mechanisms of choice and influence of attitudes and perceptions on the choice process. Swait (20) proposed a choice set generation model that belongs to the generalized extreme value (GEV) class of models. Cantillo and Ortuzar (25) employ attribute thresholds to eliminate alternatives from the choice set, with the attribute thresholds varying across individuals based on socio-economic and demographic characteristics.

\section{MODEL STRUCTURE}

The model structure used in the research effort is based on Manski's (22) original two-stage choice paradigm. The adopted structure includes a probabilistic choice set generation model in the first stage, followed by modeling discrete-continuous choice dimensions in the multiplediscrete context given the choice set from the first stage.

The first stage uses a probabilistic choice set generation mechanism because the actual choice set of alternatives is unobserved to the analyst and, therefore, cannot be determined with certainty by the analyst. Within the class of probabilistic choice set generation models, this paper adopts the Swait and Ben-Akiva (24) random constraint-based approach to choice set formation. In the random constraint-based approach, an alternative is included in the choice set if the consideration utility for that alternative is greater than some threshold consideration utility level. The consideration utility is allowed to vary across individuals, so that the consideration probability of each alternative varies across individuals.

The second stage model, given the choice set, is based on the MDCEV approach (18). At this stage, the traditional random utility maximizing process is at play wherein utilities of the alternatives in the choice set are compared directly with each other. The difference in the process at the choice set generation and choice determination stages enables a change in an attribute associated with an alternative to have two separate effects: a consideration effect (i.e., the impact on the consideration set of alternatives) and a choice effect (i.e., the impact on the choice of an alternative, given that the alternative is considered by the individual).

The model formulation in this section is developed assuming that all alternatives are feasible for each individual. Let the consideration utility of alternative $i(i=1,2, \ldots, I)$ for individual $q$ be $U_{q i}$. The alternative is included in the choice set if this consideration utility

exceeds a certain threshold and is eliminated otherwise. As the threshold is not observed by the analyst, it is considered a random variable. In the current study, this random threshold is assumed 
to be standard logistically distributed. Then, the probability that alternative $i$ is considered by individual $q$ can be written as:

$$
M_{q i}=\frac{1}{1+\exp \left(-\delta^{\prime} w_{q i}\right)}
$$

where $w_{q i}$ is a column vector of observed attributes for individual $q$ and alternative $i$ (including a constant) and $\delta$ is a corresponding column vector of coefficients to be estimated (this set of coefficients provides the impact of characteristics on the consideration probability of alternative i). Given the previous expression, the threshold is a function of individual, socio-demographic and environmental characteristics $\left(\delta^{\prime} w_{q i}\right)$. Next, assume that the randomly-distributed threshold for each alternative is independent of the threshold values of other alternatives. The overall probability of a choice set $c$ for individual $q$ may then be written as:

$$
P_{q}(c)=\frac{\prod_{i \in c} M_{q i} \prod_{j \notin c}\left(1-M_{q j}\right)}{1-\prod_{i=1}^{I}\left(1-M_{q i}\right)}
$$

where the denominator is a normalization to remove the choice set with no alternatives in it. In the second stage comprising the MDCEV model, the choice of an alternative or set of multiple alternatives from a given choice set can be written as (18):

$$
\begin{aligned}
& \left(P_{q} \mid c\right) \\
& =\frac{1}{\sigma^{M-1}}\left[\prod_{i=1}^{M} c_{i}\right]\left[\sum_{i=1}^{M} \frac{1}{c_{i}}\right]\left[\frac{\prod_{i=1}^{M} e^{V_{i} / \sigma}}{\left(\sum_{k=1}^{K} e^{V_{k} / \sigma}\right)^{M}}\right](M-1) !
\end{aligned}
$$

where

$$
c_{i}=\left(\frac{1-\alpha_{i}}{e_{i}^{*}+\gamma_{i}}\right)
$$

$e_{i}^{*}$ is the mileage traveled corresponding to alternative $i$, $\gamma_{i}$ and $\alpha_{i}$ are parameters associated with alternative $i$

$M$ is the total number of alternatives chosen by individual $q$, $V_{i}=\beta^{\prime} w_{q i}+\left(\alpha_{i}-1\right) \ln \left(\frac{e_{i}^{*}}{\gamma_{i}}+1\right)(i=1,2,3, \ldots, I)$ is the utility associated with alternative $i$,

$\beta^{\prime}$ is a vector of coefficients associated with vector of observed attributes $w_{q i}$

Based on the restrictions imposed on $\gamma_{i}$ and $\alpha_{i}$ (parameters that represent satiation effects), different specifications of the MDCEV may be obtained (see Bhat (18) for more details on the $\gamma_{i}$ and $\alpha_{i}$ parameters as well as the different specifications that result). Finally, the unconditional probability of choice of alternative $i$ may be derived as:

$$
P_{q}=\sum_{c \in G}\left(P_{q} \mid c\right) \cdot P_{q}(c),
$$


where $G$ is the set of all nonempty subsets of the master choice set of all alternatives. The membership of $G$ could include ( $2^{I}-1$ ) elements.

\section{DATA}

The data used in this study is derived from the 2009 National Household Travel Survey (NHTS) conducted in the United States. The 2009 NHTS collected detailed information on more than one million trips undertaken by 320,000 individuals from 150,000 households sampled from all over the country. The survey also collected detailed information on individual and household sociodemographic and employment-related characteristics.

The focus of this paper is on modeling non-work travel behavior for employed individuals. In order to have a manageable data sample for the modeling effort of this study, only the survey subsample corresponding to employed individuals residing in the San Francisco Bay Area of California was used. San Francisco was chosen for two main reasons. First, San Francisco has a substantially higher share of transit ridership compared to many parts of the country. Second, we have prepared detailed built environment data for the San Francisco urban region. While the 2009 NHTS data set does not, at this time, include geocoded residential and activity location information, it is anticipated that this information will become available in some form in the near future. When that happens, the built environment data we have for the San Francisco area can be used for further research.

The process of generating the estimation sample for analysis involved several steps. First, only employed individuals aged 18 years and above that participated in at least one work activity episode were selected. Second, only those who provided travel information for a weekday were included in the estimation sample. Third, a small sample of individuals that traveled for unusually long distances was excluded from the estimation sample (less than one percent). Fourth, records that contained incomplete information on individual, household, activity and travel characteristics were removed from the sample. Finally, several consistency checks were performed and records with missing or inconsistent data were eliminated. After the data cleaning process, the final estimation sample contained 1128 person observations.

The non-work activity participation information was organized for each individual in a manner consistent with the model formulation adopted in this paper. Tours were defined as per the categories identified earlier, with each tour corresponding to a period in relation to the work episode(s). Once non-work activities were placed into the appropriate tours and time-of-day periods, the vehicle miles traveled for non-work activities is aggregated within each period to obtain the continuous mileage variable. These measures were computed separately for auto, transit, and non-motorized modes of transportation resulting in a total of 15 possible alternatives for each individual (five time periods crossed with three modes of transportation). However, as the transit and non-motorized mode samples were very small, the ten alternatives associated with these modes of transport had to be collapsed into a single non-auto alternative. With this consolidation of alternatives, the final number of alternatives in the universal choice set is six five auto alternatives and one non-auto alternative.

The mileage computation considers only the distance traveled for non-work travel (activities). In the database, trip distance was self-reported. Hence, it is possible for some individuals to have zero mileage for all six alternatives. Indeed, it is found that 31.4 percent of the sample does not pursue any non-work activities in an entire day. To facilitate the estimation of the MDCEV model, a very small mileage ( 0.2 miles) is added to the non-auto mode alternative for individuals who did not report any intermediate stops. This small manipulation is 
primarily undertaken to ensure that the MDCEV model can be estimated, and has no impact on model estimation results.

Table 1 provides a summary of select household and personal characteristics for the final sample used for estimation. The analysis reveals a slightly higher proportion of females and individuals aged over 50 years in the sample. At the household level, about 80 percent of the households have either one or two adults, with nearly 56 percent of the households reporting having no children. The focus on employed individuals and the San Francisco Bay area appears to result in a substantial proportion of high income ( $>\$ 100,000$ per year) households. The table also shows sample statistics for non-work activity participation by time period and associated travel mileage. Mileage statistics are reported for the subsample that actually participated in a non-work activity within any specified time period. It should be noted that the sample shares of the chosen alternatives do not add up to 100 percent because individuals can participate in more than one activity, and in more than one time period, in a day. The descriptive statistics suggest that there is a higher inclination to undertake non-work activities after work (during work to home and after work tours) than before work. As described in earlier literature $(11,29)$, trip chaining on the way from work to home is more prevalent than trip chaining on the way to work from home. As expected, the average mileage for the non-auto alternative is lower than for auto alternatives. Also, non-work related travel mileage is lower in the context of home-to-work and work-to-home tours; this finding is consistent with the notion that non-work stops made on the way to or from work are likely to constitute minor deviations from the home $\leftrightarrow$ work axis (path). It should be noted that only the additional mileage that can be clearly attributed to the non-work activity or stop is included in the computations of mileage in this table.

\section{MODEL ESTIMATION RESULTS}

This section presents detailed description of the model estimation results. A variety of explanatory variables were considered in the model specification including individual sociodemographics, household socio-demographics, work-related characteristics, mobility and situational characteristics, and household location characteristics. Work-related characteristics captured the nature of work schedules and the flexibility associated with the schedules. The mobility and situational variables captured information on habitual (usual) travel undertaken by the individual (during the past week) and information about the specific trip. Household location variables captured the effect of urban area size, but in the absence of geocoded household location information, it was not possible to append a richer set of built environment attributes.

Before discussing the detailed model estimation results, it is useful to review the goodness-of-fit statistics of alternative model forms to assess whether the latent MDCEV model structure offers a superior data fit in comparison to a model that does not account for latent choice set generation processes. For this effort, three models were estimated. First, the latent MDCEV model proposed in this paper was estimated to give due consideration to the choice set generation process unobserved by the analyst. Second, a pure MDCEV was estimated as a restriction of the latent MDCEV using the same choice specification as the latent MDCEV but without the choice set generation component. Third, an independent specification of the pure MDCEV model was developed, including other variables that did not appear in the choice specification of the latent MDCEV model. Interestingly, in the current empirical analysis, the third model collapsed to the specification of the second model based on statistical significance of variable effects. So, we compared the first and second models in more detail based on variable effects and data fit (due to space constraints, we do not present the full model results of the pure 
MDCEV specification in the paper, but these are available from the authors). The comparison of these model results highlights three primary differences in variable effects. First, a large number of variables turned out to be statistically insignificant in the pure MDCEV model (including the Asian male, age between 18 and 30 years, female with very young children, flexible work start time, and household location variables). Second, the effects of variables on the choice process differed substantially across the two models. Finally, some of the variables that were included in the latent MDCEV model in both stages had inflated estimates in the pure MDCEV model, reinforcing the idea that the pure MDCEV co-mingles effects of variables on choice set formation and the choice decision. From a data fit standpoint, the log-likelihood measure for the latent MDCEV model is -3129.6 with 74 parameters. The corresponding figure for the pure MDCEV model is much lower at -6617.6 with 69 parameters. Although the improvement in loglikelihood measures is readily apparent, it is useful to undertake a more rigorous statistical test to compare the model fits. The two models are not directly nested within one another thus eliminating the possibility of using the likelihood ratio test for comparing model specifications. Therefore, the adjusted $\rho^{2}$ test statistic and the Bayesian Information Criterion (BIC) measure are used to compare the two model forms. The adjusted likelihood ratio index compares the fit of the estimated model with respect to the log-likelihood at the market shares according to the following equation:

$$
\rho^{2}=1-\frac{L(\hat{\beta})-M}{L(c)}
$$

where $L(\hat{\beta})$ and $L(c)$ are the log-likelihood function at convergence and market shares respectively, and $M$ is the number of estimated parameters (excluding the constants of the choice model). The adjusted likelihood ratio index for the latent MDCEV model is 0.608, while that for the pure MDCEV model is 0.182. The results indicate that the latent MDCEV is substantially preferred over the MDCEV. The Bayesian Information Criterion (BIC) is given by the expression:

$$
B I C=-2 L(\hat{\beta})+M \cdot \ln (N)
$$

where $L(\hat{\beta})$ is the log-likelihood function at convergence, $M$ is the number of parameters, and $N$ is the sample size. The model with the lower BIC value is the preferred one. The BIC value for the latent MDCEV model is 6779.3, which is substantially lower than that for the MDCEV model which has a BIC of 13720.1. These results clearly illustrate the superior data fit offered by the latent MDCEV model.

A number of alternative model forms were explored for the MDCEV component of the model. In this study, it was found that the data fit was superior for the gamma profile (18), a specification in which the $\alpha$ value is set to zero for all alternatives and separate $\gamma$ parameters are estimated for each alternative. The final model specification was obtained in a systematic manner by adding variables sequentially and examining the coefficients with respect to statistical significance, sign and magnitude, and intuitive behavioral plausibility. The selection of variables was also driven by insight from earlier empirical work on non-work activity participation and travel mileage modeling. Various forms of the explanatory variables, including non-linear, spline, and interaction effects, were considered and tested. The final specification obtained after this judicious procedure is presented in Table 2. 


\subsection{Latent Choice Set Generation Component}

Estimation results for the latent choice set generation model component are presented in Table 2a. In general, the model is found to offer plausible behavioral interpretations across a wide range of explanatory variables.

In the context of individual characteristics, it is found that older individuals are less likely to consider the before work period for undertaking non-work activities, perhaps a reflection of the greater household responsibilities that these individuals have, particularly in the early part of the day. Females, long known to shoulder a greater share of household maintenance responsibilities, are more likely to consider the work-to-home journey or the after work period for undertaking non-work activities. Cultural differences are observed with Asians less likely to consider work-based period for non-work activity engagement, while Hispanic men are disinclined to consider the home-to-work or work-to-home journey for undertaking non-work travel; these individuals possibly use alternative modes of transportation, which are less conducive to trip chaining non-work activities with the commute. More research on ethnicity based travel preferences might shed more light on this issue. Further, those without driver's license have an increased propensity to consider the non-auto alternative.

Among household characteristics, individuals in larger households are prone to considering the after-work period for undertaking non-work activities, a finding consistent with expectations. These households may have child care, spatial proximity, and vehicular availability constraints that motivate the scheduling of maintenance and recreational activities in the after-work period. Individuals in households with young children are less likely to use nonauto modes, presumably due to the need to transport small children easily. Individuals in households with school-age children, on the other hand, are more likely to consider the workbased period for non-work activities. This may be due to parents completing some errands while at work, due to the constraints associated with taking care of children after work. Greater vehicle availability is associated with consideration of the before work period, low income households tend to more inclined to include the non-auto alternative in their consideration choice set, and those in a medium income bracket tend to be less inclined to consider the before-work period for non-work activity engagement. Home owners are more likely to consider the work-to-home tour as an opportunity for undertaking non-work activities, presumably because such trip chaining brings about efficiencies in activity engagement.

Individuals with flexible work schedules (individuals who reported that they can set their own start work time) appear to be more inclined to include the work-to-home journey in their consideration set. It is possible that individuals with flexible work hours work later schedules, thus leading to this result. People who have more than one job also appear to seek efficiency by considering trip chaining of non-work activities in the work-to-home tour, and avoiding consideration of the after-work period. Self-employed individuals appear to be more oriented towards seeking the pursuit of non-work activities in the early part of the day - before work, during the journey to work, or while at work. It is possible that these individuals have greater flexibility in the beginning part of the day and work a later schedule, thus eliminating consideration of later segments of the day for non-work activities. Individuals whose distance to work is less than two miles are more likely to consider the before work alternative compared to others. As these individuals live close to the work place, trip chaining is not likely to offer much efficiency gains. Moreover these individuals may bike or walk to work, thus necessitating the pursuit of non-work activities in the before work period. 
Among the mobility and situational characteristics, variables indicating the number of bike and walk trips in the past week (a measure of the propensity to use non-motorized modes) are positively associated with consideration of the non-auto alternative. When the trip is undertaken alone, individuals are less likely to consider virtually all auto alternatives except for the work-to-home journey for undertaking non-work activities, presumably because solo errands are probably most efficiently accomplished on the way home from work. Mondays are usually the first day back at work after the weekend. It is possible that individuals are more tired on Mondays after work or have accomplished errands on the weekend days preceding the Monday. Individuals are more prone to consider the before-work period for non-work activities and less likely to consider the after-work period for a non-work activity. The positive coefficient associated with the before-work period may be a manifestation of the "Starbucks effect" (8) being more pronounced on Mondays than other days of the week. On Fridays, individuals are less prone to consider the work-based period, perhaps because individuals can undertake nonwork activities after the work period.

Only limited location variables could be considered in this study due to the absence of detailed location information for households. Individuals that do not reside in an urban area are less likely to consider the after-work period possibly because their access to destinations is poorer in non-urban areas. Individuals residing in urban areas of size less than one million population are less likely to consider the work-based period for undertaking non-work activities. In addition, those who reside in larger areas with access to subway or rail, are less likely to consider the work-to-home tour for such activities, possibly because there is greater use of rail in these metro areas that deters trip chaining of non-work activities with the commute journey.

\subsection{The MDCEV Model Component}

Results of the MDCEV model component estimation are presented in Table 2b. Younger individuals are found to be less inclined to pursue non-work activities while at work or in the after-work period. This finding is consistent with the notion that younger individuals may not have the household errands and child-related activities that would necessitate the pursuit of nonwork activities during these periods. As the number of adults in a household increases, the likelihood of pursuing non-work activities in the before work period, during the home-to-work journey, or in the after-work period decreases, presumably due to greater household constraints. In addition, the ability to allocate tasks among multiple adult members reduces the need for each individual to pursue non-work activities. Chatman (15) also found that increases in household size are associated with reductions in daily vehicle miles of travel.

The presence of children has important consequences for the participation in and mileage for non-work activities. Workers in households without children are less likely to participate in non-work activities during the home-to-work commute, presumably because they do not have to drop off children at school or day care on the way to work. Households with young children are less likely to pursue non-work activities in the after-work period, presumably because of child care constraints and the fact that very young children sleep early. Those with school age children, on the other hand are more likely to engage in non-work activities on the way home from work or in the after-work period, as they take care of household maintenance obligations and child-related activities. These findings are consistent with those reported in the literature by Rajagopalan et al. (17), who found that the presence of young children induces more non-work stops on the journey home from work, and by Boarnet et al. (14) who found that persons in households with more children accumulate more mileage for non-work activities. As expected, 
females with very young children are less likely to pursue non-work activities during all periods of the day, except on the journey home from work. This finding is consistent with the explanation that females with very young children are likely constrained by child-care responsibilities, and choose the journey home from work for accomplishing non-work errands for efficiency purposes.

Individuals in multiple worker households tend to accumulate more non-work activity engagement and mileage in the early part of the day, a finding consistent with that reported earlier by Strathman et al. (11). It is possible that individuals in multiple worker households are more constrained in the after-work period and attempt to fulfill non-work activity needs in the early part of the day. Individuals in households with more drivers are more likely to accomplish non-work activities before work, possibly due to vehicle availability constraints.

Workers with more than one job are less inclined to pursue non-work activity engagement during the commute to and from work. This is consistent with expectations as these individuals are likely to be more constrained by multiple work schedules and cannot afford to undertake additional activities during the commute. Those with a part time job, on the other hand, are likely to have more time available in the before work period, thus motivating the pursuit of non-work activities in this period. On the other hand, they are less likely to pursue non-work activities in the work-based period, presumably because that period is shorter for them. When the distance to work is less than two miles, individuals are more likely to pursue non-work activities after work. Due to their proximity to the work place, these individuals might find it convenient to reach home and undertake an entirely separate tour for non-work activities. Also, these individuals may be using alternative modes of transportation that make trip chaining of non-work activities less convenient.

Explanations for the influence of mobility and situational characteristics are less intuitive. Workers traveling alone are less prone to undertake non-work activities during the journey from work to home or in the after-work period. The negative coefficient in the after-work period may be explained by arguing that non-work activities in this period tend to involve multiple household members. However, the negative coefficient associated with the work-to-home tour is more difficult to explain. It is possible that individuals tend to undertake solo non-work activities/errands during the earlier part of the day when other household constraints are not present. Another finding difficult to explain is the negative coefficient associated with Friday for the after-work period. One would expect this to have a positive coefficient as individuals are more inclined to undertake non-work activities on Friday after work. The variables related to the frequency of non-motorized travel in last week were included to represent behavioral traits of inclination towards using non-motorized travel. The variable results in an expected effect on the choice process.

Workers living in urban areas with population less than one million are found to travel more miles for non-work activities during after-work time period, while those in larger urban areas with access to rail or subway travel more miles for non-work activities in the before work tour. The latter finding may be due to the higher prevalence of transit mode use for the journey to work, making it more challenging to couple non-work activities with the journey to and from work. All satiation parameters are statistically significant suggesting that there are substantial satiation effects in the pursuit of non-work activities and associated travel mileage for all periods of the work day. 


\section{CONCLUSIONS}

This paper aims to offer a model system capable of estimating participation in and travel mileage devoted to non-work activities and related travel during various time blocks of the day for workers. The study of non-work activity-travel engagement has been a topic of much interest, both from the perspective of developing models to accurately forecast such travel and from the perspective of being able to implement transportation control measures that may help manage the demand for such travel. In this paper, non-work activity-travel engagement is modeled for workers considering various time-of-day blocks during which such activities can be undertaken. These time-of-day blocks constitute periods of the day defined around work schedules that invariably influence activity-travel patterns for employed individuals.

The model system presented in this paper may be considered a high-level model capable of forecasting non-work activity participation in multiple time periods and the travel mileage allocated to such activities in each of the time periods. In other words, the model system recognizes that there may be multiple discreteness in the choice process, and a continuous choice dimension (travel mileage) closely tied to the multiple discrete choice process. The multiple discrete-continuous extreme value (MCDEV) modeling approach is adopted in the paper to accommodate this choice process. The model system jointly models participation in and travel mileage devoted to non-work activity-travel engagement with explicit recognition of compensatory choice behavior that may exist as individuals choose one or more time-of-day blocks within which to pursue non-work activities.

The novel element added in this paper is a first stage non-compensatory probabilistic choice set generation model that is capable of determining the consideration choice set for each individual as a function of socio-economic, demographic, and mobility attributes. In adding this component to the model system, the authors explicitly recognize that not all time-of-day periods may be considered by an individual for pursuing non-work activities. The modeling approach recognizes that the choice set generation process is latent, or unobserved, to the analyst and therefore probabilistic in nature. While probabilistic choice set generation has been incorporated previously in the context of single discrete choice modeling situations, it has virtually never been accounted for in the context of a multiple discrete-continuous modeling situation such as that considered in this paper. The two stage model system, including a probabilistic choice set generation component coupled with a MDCEV model component, is formulated and presented in the paper.

The model system is applied to a travel survey sample belonging to the San Francisco Bay Area drawn from the 2009 National Household Travel Survey of the United States. Both a two-stage model system including a latent choice set generation model component and a MDCEV model component, as well as a pure single-stage MDCEV model that assumes a constant (complete) choice set for all individuals, are estimated on the survey sample. A comparison of the measures of fit across the two model structures shows that the latent MDCEV specification offers vastly superior performance, thus pointing to the critical importance of considering latent choice set generation processes in the modeling of discrete-continuous choice decisions such as those considered here. The choice set generation model component clearly indicates that the consideration set of each individual is different, and highly dependent on a range of explanatory variables that describe the individual, household, and mobility and situational attributes. This suggests that future travel survey collection efforts seriously consider eliciting choice set formation data, so that models may be based directly on the choice set formation information rather than using latent choice set generation approaches. In the absence 
of such data, our research results suggest that activity-based travel microsimulation model systems that purport to replicate individual and household activity-travel choices incorporate probabilistic latent choice set generation model components to fully capture the decision processes at play. Models estimated using simplistic and deterministic choice set generation rules, or assuming constant choice sets for all individuals, are inevitably going to provide inaccurate parameter estimates and consequently, poor forecasts of travel under a wide range of policy and socio-economic scenarios. This paper offers a straightforward and practical approach for incorporating probabilistic latent choice set generation model components into activity-travel model systems. The research in this paper may be extended to include detailed built environment variable effects once spatial attributes of activity locations become available in the NHTS data. In addition, from a practical implementation standpoint, further downstream models of activity scheduling in time and space (including activity purpose of non-work stops, time-of-day, chaining, and location choice) will need to be estimated so as to be consistent with the predictions provided by the higher-level joint participation-mileage model presented in this paper.

\section{ACKNOWLEDGEMENTS}

The authors acknowledge the helpful comments of five anonymous reviewers on an earlier version of the paper. The authors are grateful to Lisa Macias for her help in typesetting and formatting this document. 


\section{REFERENCES}

1. Pendyala, R. M., and R. Kitamura. The Rapid Motorization of Asia: Implications for the Future. Transportation, Vol. 34, No. 3, 2007, pp. 275-279.

2. Polzin, S. E. The Case for Moderate Growth in Vehicle Miles of Travel: A Critical Juncture in U.S. Travel Behavior Trends. Final Report, U.S. Department of Transportation, Office of the Secretary, Washington, D.C., 2006.

3. Toole-Holt, L., S. E. Polzin, and R. M. Pendyala. Two Minutes per Person per Day Each Year: Exploration of Growth in Travel Time Expenditures. In Transportation Research Record: Journal of the Transportation Research Board, No. 1917, Transportation Research Board of the National Academies, Washington, D.C., 2005, pp. 45-53.

4. Gordon, P., A. Kumar, and H. W. Richardson. Beyond the Journey to Work. Transportation Research Part A, Vol. 22, No. 6, 1988, pp. 419-426.

5. Lockwood, P. B., and M. J. Demetsky. Nonwork Travel: A Study of Changing Behavior. Presented at the 73rd Annual Meeting of the Transportation Research Board, Washington, D.C., 1994.

6. Strathman, J. G., and K. J. Dueker. Understanding Trip Chaining. 1990 NPTS Special Reports on Trip and Vehicle Attributes. Publication FHWA-PL-95-033. FHWA, U.S. Department of Transportation, 1995.

7. Hu, P. S. and J. R. Young. Summary of Travel Trends: 1995 Nationwide Personal Transportation Survey. Publication FHWA-PL-00-006, FHWA, U.S. Department of Transportation, 1999.

8. McGuckin, N., J. Zmud, and Y. Nakamoto. Trip-Chaining Trends in the United States: Understanding Travel Behavior for Policy Making. In Transportation Research Record: Journal of the Transportation Research Board, No. 1917, Transportation Research Board of the National Academies, Washington, D.C., 2005, pp. 199-204.

9. Adler, T. J., and M. Ben-Akiva. A Theoretical and Empirical Model of Trip Chaining Behavior. Transportation Research Part B, Vol. 13, No. 3, 1979, pp. 243-257.

10. Horowitz, J. A Utility Maximizing Model of the Demand for Multi-Destination Non-Work Travel. Transportation Research Part B, Vol. 14, No. 4, 1980, pp. 369-386.

11. Strathman, J. G., K. J. Dueker, and J. S. Davis. Effects of Household Structure and Selected Travel Characteristics on Trip Chaining. Transportation, Vol. 21, No. 1, 1994, pp. 23-45.

12. Bowman, J. L., and M. Ben-Akiva. Activity-Based Disaggregate Travel Demand Model System with Activity Schedules. Transportation Research Part A, Vol. 35, No. 1, 2000, pp. 1-28.

13. Wen, C. H., and F. S. Koppelman. A Conceptual and Methodological Framework for the Generation of Activity-Travel Pattern. Transportation, Vol. 27, No. 1, 2000, pp. 5-23.

14. Boarnet, M. G., K. S. Nesamani, and C. S. Smith. Comparing the Influence of Land Use on Nonwork Trip Generation and Vehicle Distance Traveled: An Analysis Using Travel Diary Data. Presented at the 83rd Annual Meeting of the Transportation Research Board, Washington, D.C., 2004.

15. Chatman, D. Deconstructing Development Density: Quality, Quantity and Price Effects on Household Non-Work Travel. Transportation Research Part A, Vol. 42, No. 7, 2008, pp. 1008-1030.

16. Bhat, C. R., and S. K. Singh. A Comprehensive Daily Activity-Travel Generation Model System for Workers. Transportation Research Part A, Vol. 34, No. 1, 2000, pp. 1-22. 
17. Rajagopalan, B. S., A. R. Pinjari, and C. R. Bhat. Comprehensive Model of Worker Nonwork-Activity Time Use and Timing Behavior. In Transportation Research Record: Journal of the Transportation Research Board, No. 2134, Transportation Research Board of the National Academies, Washington, D.C., 2009, pp. 51-62.

18. Bhat, C. R. The Multiple Discrete-Continuous Extreme Value (MDCEV) Model: Role of Utility Function Parameters, Identification Considerations, and Model Extensions. Transportation Research Part B, Vol. 42, No. 3, 2008, pp. 274-303.

19. Williams, H. C., and J. D. Ortuzar. Behavioral Theories of Dispersion and the MisSpecification of Travel Demand Models. Transportation Research Part B, Vol. 16, No. 3, 1982, pp. 167-219.

20. Swait, J. Choice Set Generation within the Generalized Extreme Value Family of Discrete Choice Models. Transportation Research Part B, Vol. 35, No. 7, 2001, pp. 643-666.

21. Basar, G., and C. R. Bhat. A Parameterized Consideration Set Model for Airport Choice: An Application to the San Francisco Bay Area. Transportation Research Part B, Vol. 38, No. 10, 2004, pp. 889-904.

22. Manski, C. The Structure of Random Utility Models. Theory and Decision, Vol. 8, No. 3, 1977, pp. 229-254.

23. McFadden, D. Modelling the Choice of Residential Location. In A. Karlqvist, L. Lundqvist, F. Snickars, and J. Weibull (eds) Spatial Interaction Theory and Residential Location, NorthHolland, Amsterdam, 1978, pp. 75-96.

24. Swait, J., and M. Ben-Akiva. Empirical Test of a Constrained Choice Discrete Model: Mode Choice in Sao Paulo, Brazil. Transportation Research Part B, Vol. 21, No. 2, 1987, pp. 103115.

25. Cantillo, V., and J. D. Ortuzar. A Semi-Compensatory Choice Model with Explicit AttributeThresholds of Perception. Transportation Research Part B, Vol. 39, No. 7, 2005, pp. 641657.

26. von Haefen, R. H. Latent Consideration Sets and Continuous Demand System Models. Environmental and Resource Economics, Vol. 41, No. 3, 2008, pp. 363-379.

27. Shocker, A. D., M. Ben-Akiva, B. Boccara, and P. Nedungadi. Consideration Set Influences on Consumer Decision-Making and Choice: Issues, Models, and Suggestions. Marketing Letters, Vol. 2, No. 3, 1991, pp. 181-197.

28. Ben-Akiva, M., and B. Boccara. Discrete Choice Models with Latent Choice Sets. International Journal of Research in Marketing, Vol. 12, No. 1, 1995, pp. 9-24.

29. Bhat, C. R., and R. Sardesai. The Impact of Stop-Making and Travel Time Reliability on Commute Mode Choice. Transportation Research Part B, Vol. 40, No. 9, 2006, pp. 709-730. 


\section{LIST OF TABLES}

TABLE 1 Sample Characteristics ( $\mathrm{N}=1128$ persons)

TABLE 2 Latent MDCEV Results 
TABLE 1 Sample Characteristics ( $\mathrm{N}=1128$ persons)

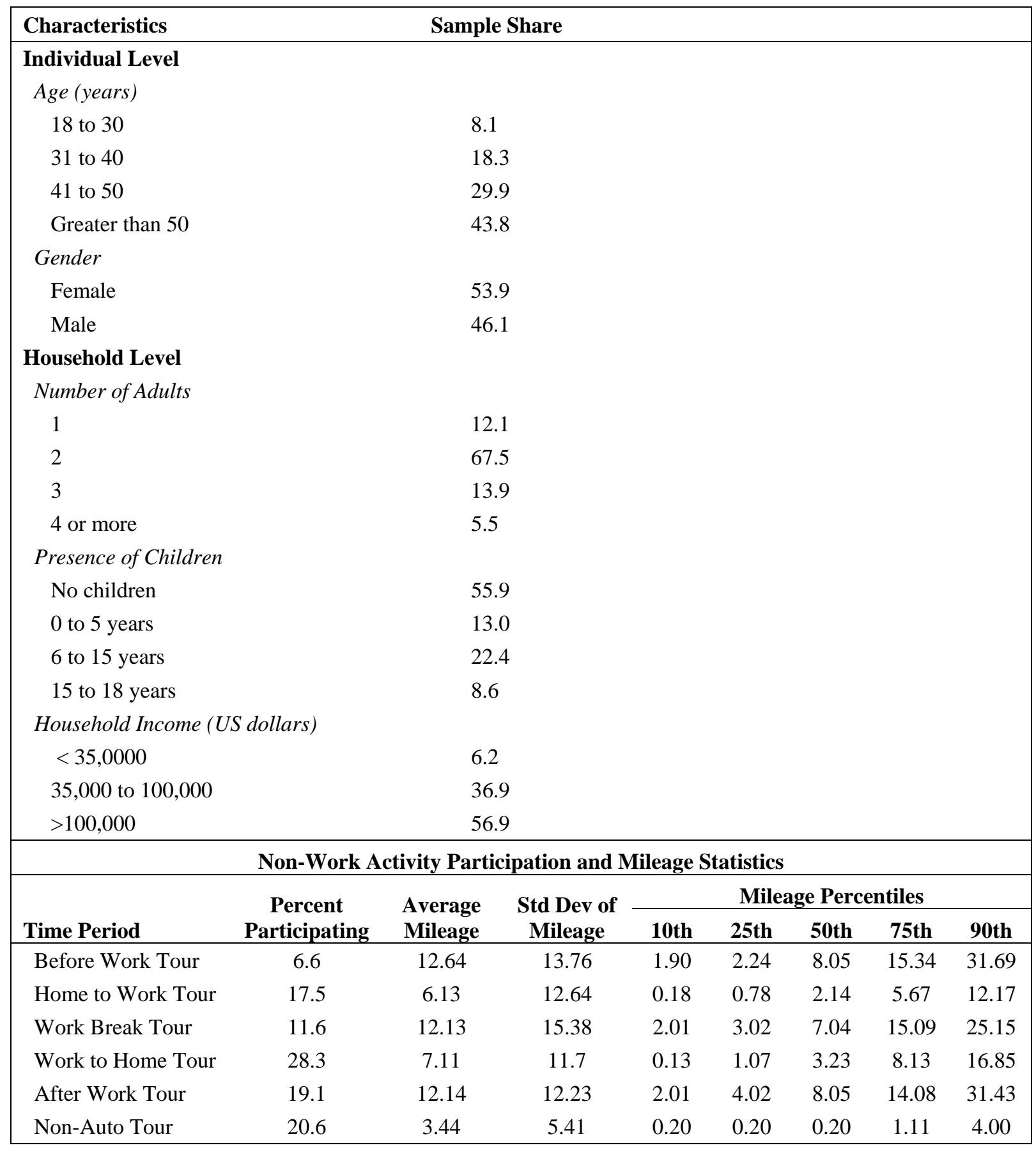


TABLE 2a Latent MDCEV Results: Latent Choice Set Generation Component

\begin{tabular}{|c|c|c|c|c|c|c|}
\hline Explanatory Variables & Before Work & Home to Work & Work Based & Work to Home & After Work & Non-Auto \\
\hline $\begin{array}{l}\text { Individual demographics } \\
\text { Age } \\
\text { Female } \\
\text { Asian } \\
\text { Asian Male } \\
\text { Hispanic Male } \\
\text { Without a driver license }\end{array}$ & $-0.0351(-2.564)$ & $\begin{aligned} 0.9101 & (1.588) \\
-1.3736 & (-1.922)\end{aligned}$ & $-1.3339(-1.913)$ & $\begin{array}{r}2.305(3.182) \\
-1.2826(-1.834)\end{array}$ & $1.0234(2.690)$ & $1.233(1.491)$ \\
\hline $\begin{array}{l}\text { Household socio-demographics } \\
\text { Number of persons } \\
\text { Presence of very young children } \\
\text { (0 to } 5 \text { years of age) } \\
\text { Presence of young children } \\
\text { (6-15 years of age) } \\
\text { Vehicle Availability (\#vehicles/\#drivers) } \\
\text { Low annual household income }(<\$ 35,000) \\
\text { Medium annual household income } \\
\text { (\$35,000-\$100,000) } \\
\text { Housing unit is owned }\end{array}$ & $\begin{array}{l}0.6814(2.424) \\
-1.101(-2.819)\end{array}$ & & $1.3786(1.891)$ & $0.8387(1.725)$ & 0.4398 (2.383) & $\begin{array}{l}-0.6746(-3.604) \\
0.4667(1.648)\end{array}$ \\
\hline $\begin{array}{l}\text { Work related characteristics } \\
\text { Flexible start time } \\
\text { Have more than one job } \\
\text { Self-employed } \\
\text { Distance to work }<2 \text { miles } \\
\end{array}$ & $\begin{array}{l}0.8217(1.856) \\
1.4025(2.892)\end{array}$ & $\begin{array}{ll}1.3739 & (1.616) \\
1.3347 & (2.524)\end{array}$ & $1.4903(2.385)$ & 1.1271 (2.538) & $-0.5454(-1.609)$ & \\
\hline $\begin{array}{l}\text { Mobility and Situational Characteristics } \\
\text { Number of bike trips in past week } \\
\text { Number of walk trips in past week } \\
\text { Trip was made alone } \\
\text { Monday } \\
\text { Friday }\end{array}$ & $\begin{array}{cl}-1.8695 & (-4.787) \\
0.9922 & (2.591)\end{array}$ & $-2.2159(-4.764)$ & $-1.8875(-2.916)$ & & $\begin{array}{l}-2.6404(-5.242) \\
-1.1145(-2.381)\end{array}$ & $\begin{array}{ll}0.0982 & (2.028) \\
0.0482 & (3.788)\end{array}$ \\
\hline $\begin{array}{l}\text { Household location variables } \\
\text { Not in urban area } \\
\text { Urban size }<1 \text { million } \\
\text { Urban size }<1 \text { million with access to } \\
\text { subway or rail }\end{array}$ & & & $\begin{array}{l}-1.2404(-2.46) \\
-1.4221(-3.191)\end{array}$ & $-1.2268(-2.630)$ & $-1.8415(-2.041)$ & \\
\hline Constant & $-0.4278(-0.549)$ & 0.9377 (1.953) & $1.8486(2.282)$ & $-0.255(-0.493)$ & $0.2235(0.334)$ & \\
\hline
\end{tabular}


TABLE 2b Latent MDCEV Results: MDCEV Component

\begin{tabular}{|c|c|c|c|c|c|c|}
\hline Explanatory Variables & Before Work & Home to Work & Work Based & Work to Home & After Work & Non-Auto \\
\hline $\begin{array}{l}\text { Individual demographics } \\
\text { Age } 18 \text { to } 30 \text { years }\end{array}$ & & & $-1.3679(-1.46)$ & & $-1.2539(-2.908)$ & \\
\hline $\begin{array}{l}\text { Household socio-demographics } \\
\text { Number of adults } \\
\text { No children } \\
\text { Presence of very young children } \\
\text { (0 to } 5 \text { years of age) } \\
\text { Presence of young children } \\
\text { (6-15 years of age) } \\
\text { Presence of old children } \\
\text { (16-18 years of age) } \\
\text { Female with very young children } \\
\text { (0 to } 5 \text { years of age) } \\
\text { More than one worker } \\
\text { Number of drivers }\end{array}$ & $\begin{array}{l}-1.2991 \quad(-1.726) \\
-3.0788 \quad(-3.291) \\
0.9598 \quad(1.232)\end{array}$ & $\begin{array}{c}-0.5979(-2.668) \\
-1.3784(-5.063) \\
\\
-1.2489(-2.446) \\
0.601(2.137)\end{array}$ & $\begin{array}{l}-2.1106(-2.592) \\
0.5729(1.799)\end{array}$ & $1.0156(4.070)$ & $\begin{array}{l}-0.3694(-1.903) \\
-0.6409(-1.550) \\
0.9832(2.688) \\
-1.8622(-2.700)\end{array}$ & \\
\hline $\begin{array}{l}\text { Work related characteristics } \\
\text { Have more than one job } \\
\text { Part Time Job } \\
\text { Distance to work }<2 \text { miles }\end{array}$ & $1.0869(1.802)$ & $-1.1408(-2.142)$ & $-1.7695(-3.038)$ & $-0.9847(-2.523)$ & $0.7032(2.170)$ & \\
\hline $\begin{array}{l}\text { Mobility and situational characteristics } \\
\text { Trip was made alone } \\
\text { Friday }\end{array}$ & & & & $-0.4622(-1.842)$ & $\begin{array}{l}-0.7167(-1.612) \\
-1.1507(-1.878)\end{array}$ & \\
\hline $\begin{array}{l}\text { Household location variables } \\
\text { Urban size }<1 \text { million } \\
\text { Urban size }>1 \text { million with access to } \\
\text { subway or rail }\end{array}$ & $0.7347(1.390)$ & & & & $0.5003(2.042)$ & \\
\hline Baseline preference constants & $-10.6954(-9.765)$ & $-10.0333(-18.504)$ & $-12.5283(-36.203)$ & $-11.7083(-46.243)$ & $-10.7257(-22.545)$ & \\
\hline Satiation Parameters $(\gamma)$ & $2.4941(4.570)$ & $0.666(2.914)$ & $2.7208(7.426)$ & $0.9664(5.345)$ & 3.2222 (8.009) & \\
\hline
\end{tabular}

Note: Figures in parentheses are $t$-statistics. 